\title{
DESIGN OF WATER HAMMER CONTROL STRATEGIES IN HYDROPOWER PLANTS
}

UDC: 621.311 .21

Original scientific paper

https://doi.org/10.18485/aeletters.2018.3.1.5

\author{
Anton Bergant ${ }^{1}$, Jernej Mazij ${ }^{1}$, Uroš Karadžic ${ }^{2}$ \\ ${ }^{1}$ Litostroj Power d.o.o., Litostrojska 50, 1000 Ljubljana, Slovenia \\ ${ }^{2}$ Faculty of Mechanical Engineering, Džordža Vašingtona bb, 81000 Podgorica, Montenegro
}

\begin{abstract}
:
Hydropower plants play an important role in the growth of the renewable energy sector. The main objective of the paper is to present, discuss and assess critical parameters which may cause unacceptable water hammer loads in hydropower plants. Water hammer is caused by flow disturbances in a conduit from one steady state to another. It induces pressure rise or drop in hydraulic systems, rotational speed variation in hydraulic turbomachinery and level fluctuation in surge tanks and air chambers. Design principles of water hammer control strategies (mitigation of excessive loads) are outlined including operational scenarios (closing and opening laws), surge control devices (flywheel, surge tank, regulating valve, air valve, etc.) or redesign of the pipeline components. Water hammer models and solutions are briefly discussed in the light of their capability. Case studies include hydropower plants with long fluid conveying systems (open channels, tunnels) and water hammer control devices (surge tank, regulating valve).
\end{abstract}

ARTICLE HISTORY

Received 10.01.2018

Accepted 26.02.2018

Available 15.03.2018

\section{KEYWORDS}

hydropower plant, water hammer control, surge tank, regulating valve, numerical analysis, field tests.

\section{INTRODUCTION}

Modern hydropower systems should be able to cover peak demands and to store surpluses of grid energy, in particular that coming from intermittent generators associated with wind and solar power. There are several key parameters associated with the design of a new or refurbishment of ageing hydropower plant including safety, efficiency, availability and profitability of the plant. Refurbished plant by definition starts from old basic infrastructure which may raise issues not encountered with new plant: some ageing components cannot be refurbished adequately (in particular civil works), changes in the role of the plant in the energy system (increased operational flexibility), increase of plant output and changes in the environment of the plant. The objective of this paper is to present, discuss and assess the critical parameters which may cause unacceptable water hammer loads in hydropower plants. Flow-induced vibrations (draft-tube surge, rotor-stator interactions) [1] are beyond the scope of this paper.

Water hammer is caused by turbine load acceptance and reduction, load rejection under governor control, emergency shutdown and unwanted runaway, and closure and opening of the safety shutoff valve. It induces pressure rise or drop in hydraulic systems, rotational speed variation in hydraulic turbomachinery (turbines, pump-turbines, storage pumps) and level fluctuation in surge tanks and air chambers. Design principles of water hammer control strategies (mitigation of excessive loads) are outlined including operational scenarios (closing and opening laws, limitation of operating conditions), surge control devices (flywheel, surge tank, regulating valve, air valve, etc.), or redesign of the pipeline components. Theoretical elastic and rigid water hammer models and solutions are briefly presented and discussed. The paper concludes with two case studies including hydropower plants with long fluid conveying systems (open channels, headrace and tailrace 
tunnels) and water hammer control devices (surge tank, regulating valve).

\section{DESIGN PRINCIPLES OF WATER HAMMER CONTROL STRATEGIES}

Large transient loads may disturb overall operation of the hydropower plant and damage the system components. Water hammer [2] can be kept within the prescribed limits (e.g. pressure in the flow-passage system, turbine rotational speed, surge tank water level, etc.) with the following methods:

(1) alteration of operational regimes,

(2) installation of surge control devices in the system,

(3) redesign of the flow-passage system layout.

\subsection{Alteration of operational regimes}

Alteration of operational regimes includes appropriate regulation of the wicket gate and runner blade maneuvers in reaction turbines, and turbine distributor (needle valve) and jet deflector maneuvers in impulse turbines. Typically a twospeed wicket gate closing time function (adding a cushioning stroke) significantly improves reaction turbine safe operation. Opening of runner blades during Kaplan or bulb turbine shutdown (normal, mechanical quick stop, emergency) results in favourable blade operation, improved over-speed performance and reduced negative axial hydraulic thrust. Appropriate setting of closing/opening times of the shutoff valves contributes to safer operation of these devices in emergency and exceptional operating conditions. A draft tube gate can be used to protect axial turbine against runaway. In addition, sluicing operation of the low-head axial turbines can attenuate open channel waves during transient regimes. Limitation of operating regimes (reduced discharge) is yet another option. This measure may be considered as temporary one before more effective method is devised.

\subsection{Installation of surge control devices}

Installation of surge control devices in the system alter the system characteristics (shorten the active conduit length, reduce the liquid compressibility, increase the turbine unit inertia). The protective devices that may be installed along the inlet and outlet conduit or added to the hydropower system components include:

(1) increased turbine unit inertia (adding flywheel to small units, increasing the generator inertia),

(2) resistors (to absorb excessive power),

(3) surge tank in headrace and/or tailrace (shortens the active conduit length, improves governing stability),

(4) air cushion surge chamber (requires compressed air supply),

(5) pressure-regulating valve (operates synchronously with the turbine wicket gates),

(6) pressure-relief valve (opens at a set pressure, small units),

(7) rupture disc (bursts at a set pressure, small units),

(8) aeration pipe (attenuates water column separation),

(9) air valve (attenuates water column separation, reduces negative axial hydraulic thrust).

\subsection{Redesign of the flow-passage system layout}

Redesign of the flow-passage system layout includes:

(1) change of water conveyance profile (high point);

(2) change of conduit dimensions (diameter, length);

(3) different position of system components (valve).

Operational, safety and economic factors are decisive for selection of the type of protection against the undesirable water hammer effects. A number of alternatives should be investigated before the final design. The most convenient water hammer control method in the hydropower plant is the alteration of operational regimes. It is expensive to install additional surge control devices in the system except if this cannot be achieved by the first method. It is rarely feasible to redesign the proposed flow-passage system. Water hammer control devices should operate smoothly in normal operating conditions. These conditions include the turbine start-up, load acceptance, load reduction and total load rejection (mechanical quick stop, electrical emergency shutdown). Emergency conditions are load rejections in which the runner blades (axial and diagonal turbines) fail to operate or partial runaway occurs. The turbine runaway is considered as a catastrophic transient regime. Water hammer analysis should be performed for normal, emergency and catastrophic operating conditions [2].

\section{WATER HAMMER ANALYSIS}

Water hammer is the transmission of pressure waves along the pipeline resulting from a change in liquid flow velocity (discharge). It leads to higher 
dynamic loads on plant components during transient operating events (rapid load acceptance and reduction, unit shutdown). This requires a thorough transient analysis. Hydraulic transient analysis is traditionally undertaken with deterministic models [2-3] that treat a number of transient regimes based on experience, guidelines and codes. In addition, parametric analysis accounts for uncertain parameters (e.g. friction, wave speed, turbine performance characteristics). These results form the basis for risk analysis to transients in hydropower plant that includes identification of critical regimes, evaluation of the risk (low, high) and risk management (modifications to reduce the risk) [4]. It is clear the scope of analysis is dependent on the type of the machine and complexity of the plant layout.

Water hammer in hydropower plants can be calculated using either elastic or rigid water hammer theory [2-3]. The elastic liquid column model is used for the systems with relatively long tunnels and penstocks, and systems with rapid transients. Slightly compressible liquid and elastic pipe walls are assumed in the elastic column model. Unsteady flow in closed conduits is described by two one-dimensional equations; the continuity equation and the equation of motion. The hyperbolic set of equations is solved by the method of characteristics. For run-of-river power plants with relatively short inlet and outlet conduits the rigid column model is recommended. In this case the length of the conduit is of the same order as the cross-sectional dimensions. Incompressible liquid and rigid pipe walls are assumed in the rigid column model. Rigid water hammer is described by the one-dimensional equation of motion for unsteady pipe flow. The equation can be solved numerically by using the Runge-Kutta method. Elastic and rigid column equations are solved simultaneously with the boundary condition equations (turbine, valve, surge tank, reservoir, etc.) [2-3]. The hydraulic turbomachine may undergo turbine, pump or pumpturbine operating modes. The governed turbine boundary condition is described by the turbine (head balance equation, dynamic equation of rotating masses) and the governor (dynamic equation which relates the pump-turbine rotational speed change to the position of the regulating mechanism(s)), and it is coupled with pipeline water hammer equations. The relationship among influential turbine variables is presented in the form of the experimentally predicted characteristics (head, torque, axial force). The complete set of the hydraulic turbomachinegovernor-pipeline equations should be used for the case of load reduction in which the turbine speed is regulated by the governor. The governor equations are omitted in analysis for the case of turbine sudden load rejection in which the unit speed change is controlled by the turbine net torque only. The theoretical description of the actual hydropower system invariably introduces assumptions and approximations [5] which may have negligible influence in certain applications but introduce significant systematic errors in other circumstances. Field test cases are needed to verify water hammer models and adequacy of design strategies.

\section{CASE STUDY 1: TURBINE EMERGENCY SHUTDOWN IN ZLATOLIČJE HPP}

The Slovenian run-off river type Zlatoličje HPP has been recently refurbished. Two old Kaplan turbines were upgraded with new runners of larger output capacity each of $80 \mathrm{MW}$. Two Kaplan units are embedded into large-scale open channel system (Fig.1). The length of the inlet channel is of $17,200 \mathrm{~m}$ and the outlet channel is $6,200 \mathrm{~m}$ long. The channels are of trapezoidal profile with its bottom and side walls concrete lined.

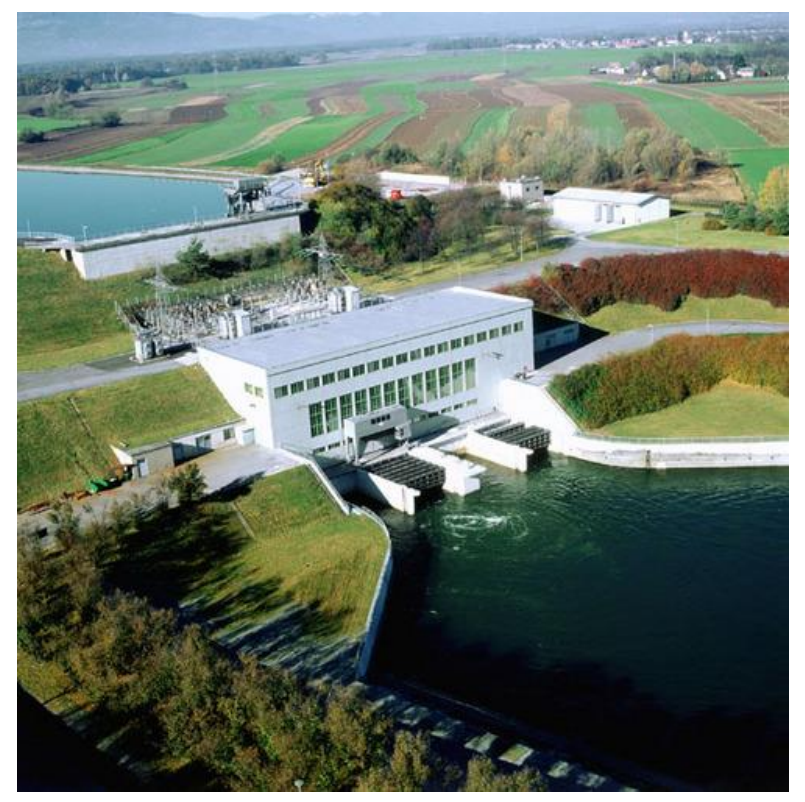

Fig.1. Layout of Zlatoličje HPP powerhouse, Slovenia

Each of the two Kaplan turbines (Fig.2) is equipped with a pressure regulating valve (PRV). The PRV is comprised of five vertical vanes connected via the rod to servomotor and controlled by the turbine governor. The continuous measurement of the channel water level at the turbine inlet, and pressures in the turbine scroll case and draft tube indicates that water level oscillations in the two open channels are small and within the prescribed limits during water 
hammer events. The PRV attenuates free surface waves in both channels [6]. Therefore, the constant water levels at the turbine inlet and the turbine outlet are assumed in water hammer calculations. Analysis of free surface waves in both channels is beyond the scope of this paper. Fig. 3 shows action of the PRV during shutdown from full-load. The detailed plant layout used for water hammer calculations can be found in Bergant et al. [6]. The length of the conduit is of the same order as the cross-sectional dimensions and the cross-sectional area is of complex shape. The standard one-dimensional elastic column water hammer model cannot accurately predict the physics of wave transmission and reflection in very short pipelines. The rigid column model is recommended to be used for this case. The dimensions of the inlet conduit, scrollcasing and draft tube used in the one-dimensional rigid water hammer model are expressed as geometrical characteristics $G_{u}=0.876 \mathrm{~m}^{-1}$ and $G_{d}=$ $0.549 \mathrm{~m}^{-1}$, respectively $(G=\Sigma(L / A) ; L=$ length, $A=$ area). Emergency shutdown of the Kaplan turbine unit from $75 \mathrm{MW}$ load is presented in this paper (Fig.4).

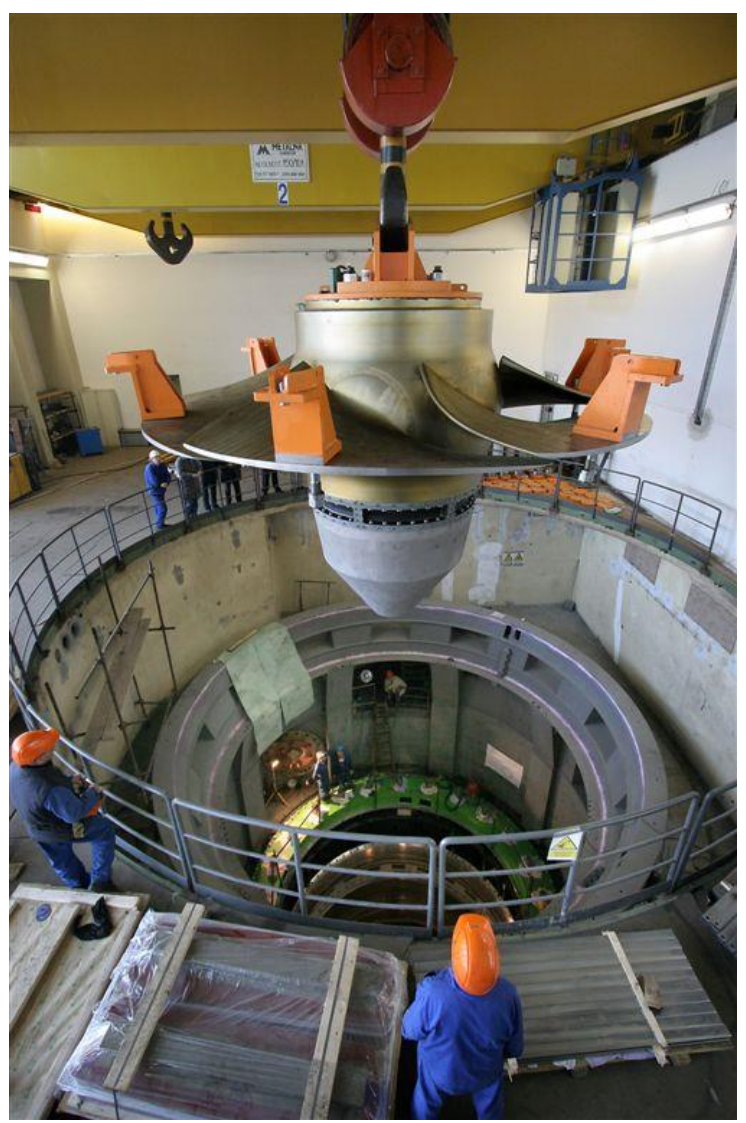

Fig.2. Lowering of $80 \mathrm{MW}$ Kaplan runner in turbine pit; Zlatoličje HPP

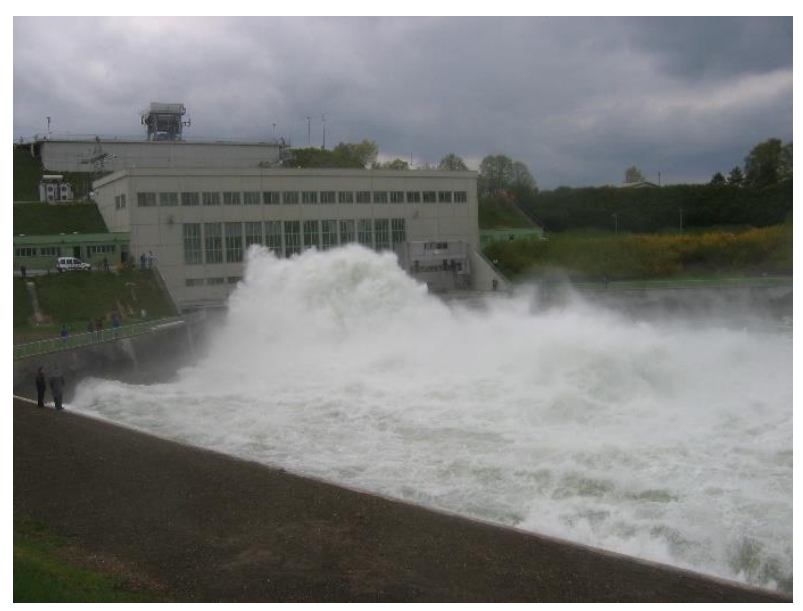

Fig.3. Action of pressure regulating valve during turbine shutdown in Zlatoličje HPP

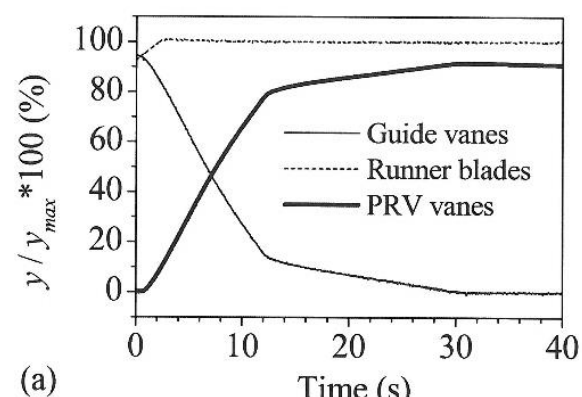

(a) Time (s)
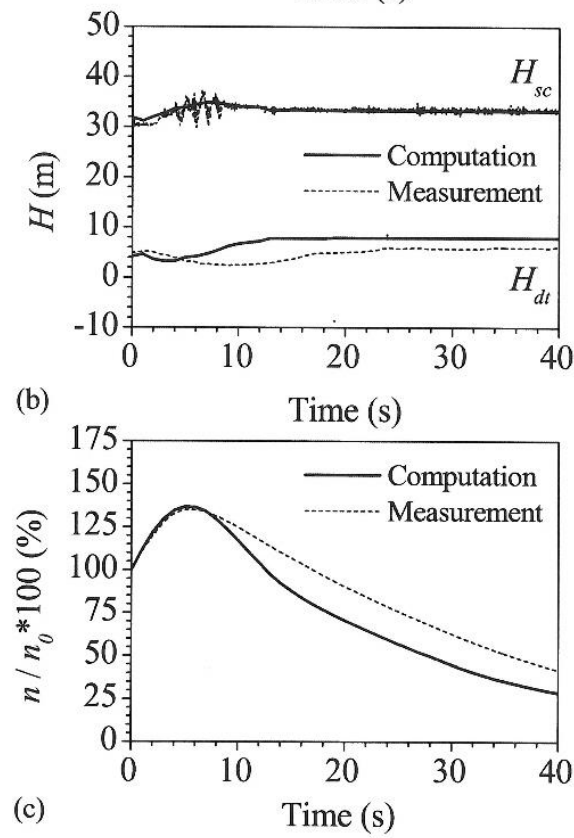

Fig.4. Emergency shutdown in Zlatoličje HPP $(P=75$ $\mathrm{MW}$ ): Guide-vane, runner-blade and PRV-vane servomotor strokes $y(a)$, scroll case and draft tube heads $H(b)$ and unit rotational speed $n(c)$ [6]

Emergency shutdown of the turbine unit from 75 MW load is of one of the most severe normal operating regimes with respect to large transient loads. The turbine is disconnected from the electrical grid followed by the complete closure of the wicket gates while the runner blades open to their fully open 
position (Fig.4a). The PRV blades first open to about $90 \%$ opening synchronously with the wicket gate closure (Fig.4a) and then start to close at a very slow rate to its fully closed position. The PRV linear fullstroke closing time is twenty minutes.

The computed maximum momentary scroll case pressure head $\left(H_{s c}\right)$ of $35 \mathrm{~m}$ practically coincides with the averaged measured one; there is a reasonable agreement between the calculated and measured draft tube pressure heads too (Fig.4b). The agreement between the computed maximum rotational speed rise of $35 \%$ and the measured one is good too (Fig.4c; $n_{0}=125 \mathrm{~min}^{-1}$ ). The maximum scroll case pressure head and the maximum speed rise are within the guaranteed limits $(43.9 \mathrm{~m}$ and $45 \%$, respectively).

\section{CASE STUDY 2: TURBINE EMERGENCY SHUTDOWN IN PERUĆICA HPP}

Montenegrian Perućica HPP is comprised of a concrete tunnel (length $3335 \mathrm{~m}$, diameter $4.8 \mathrm{~m}$ ), surge tank (Fig.5) and three parallel penstocks (Fig.6) with horizontal-shaft Pelton turbines built at their downstream ends.

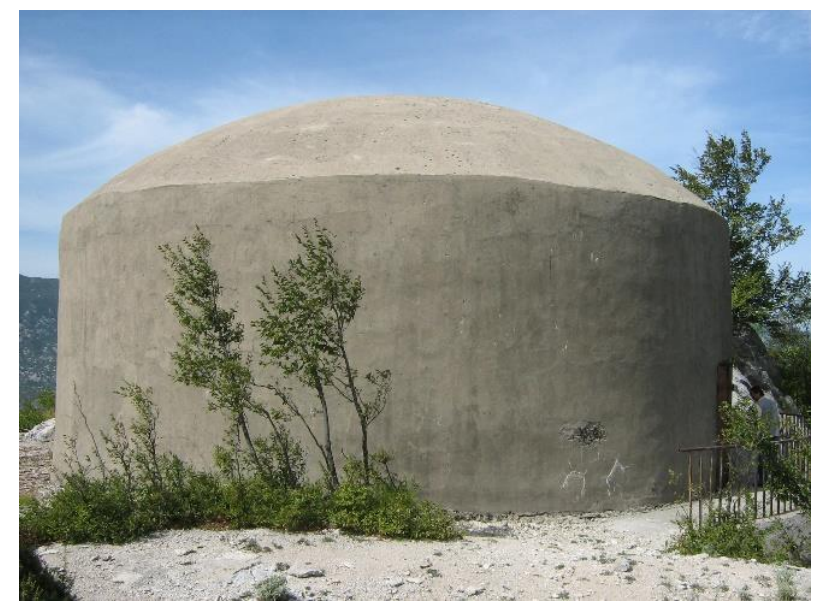

Fig.5. Above-ground layout of the surge tank in Perućica HPP, Montenegro

The maximum water level at the intake is 613 m.a.s.l. and the minimum 602.5 m.a.s.l. The surge tank is of cylindrical type (diameter 8 and $12 \mathrm{~m}$ ) with an expansion and overflow. At the surge tank intake there is a non-symmetrical orifice. The length of each steel penstock is about $2000 \mathrm{~m}$ whereby penstock I feeds two turbine units ( $\mathrm{A} 1$ and $\mathrm{A} 2$ ) with rated unit power of $39 \mathrm{MW}$ each, penstock II feeds three turbine units ( $A 3, A 4$ and $A 5)$ of $39 \mathrm{MW}$ each and penstock III feeds two units (A6 and A7) of 59 MW each.

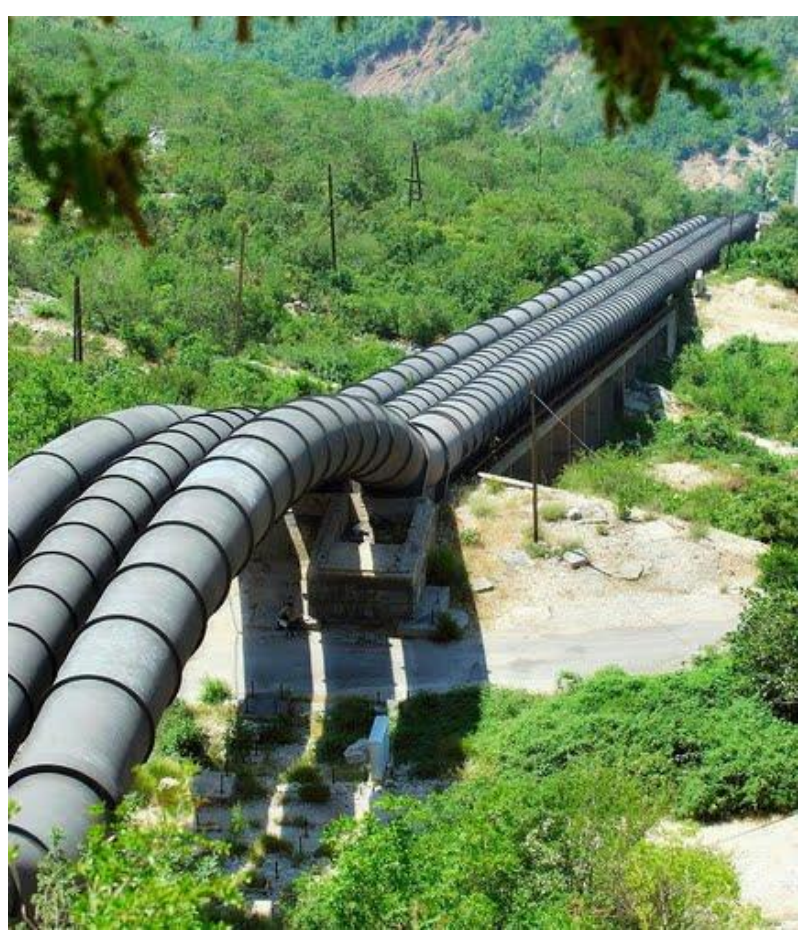

Fig.6. Layout of three parallel steel penstocks in Perućica HPP

All seven turbine units are embedded in powerhouse (Fig.7) with two tailrace tunnels (one for units $A 1$ to $A 5$, one for units $A 6$ and $A 7$ ). The runner diameter of twin type turbine units $A 1$ to $A 5$ is $2400 \mathrm{~mm}$ and for twin type turbine units $A 6$ and A7 is $2100 \mathrm{~mm}$. Two safety spherical valves are attached to each turbine unit. A detailed description of the Perućica HPP flow-passage system with its all main characteristics can be found in Karadžić et al [7]. Rehabilitation of turbine units has been performed in several stages. This includes supply of new distributors (needle valves) and refurbishment of the pertinent spherical valves (replacement of seals and actuating servomotors) for the first four turbine units, and finally, supply of six new Pelton wheels for $39 \mathrm{MW}$ units and three wheels for $59 \mathrm{MW}$ units.

The standard one-dimensional elastic column water hammer model is used for transient analysis because of long tunnel and penstocks. Method of characteristics based software package with a novel Pelton turbine boundary condition has been validated for a number of typical transient regimes [7] in Perućica HPP. Emergency shutdown of turbine unit $\mathrm{A} 1$ from initial power of $39.5 \mathrm{MW}$ is presented in this paper (Fig.8). The corresponding discharge in the penstock I: $8.4 \mathrm{~m}^{3} / \mathrm{s}$, penstock II: no discharge and penstock III: $22 \mathrm{~m}^{3} / \mathrm{s}$. 


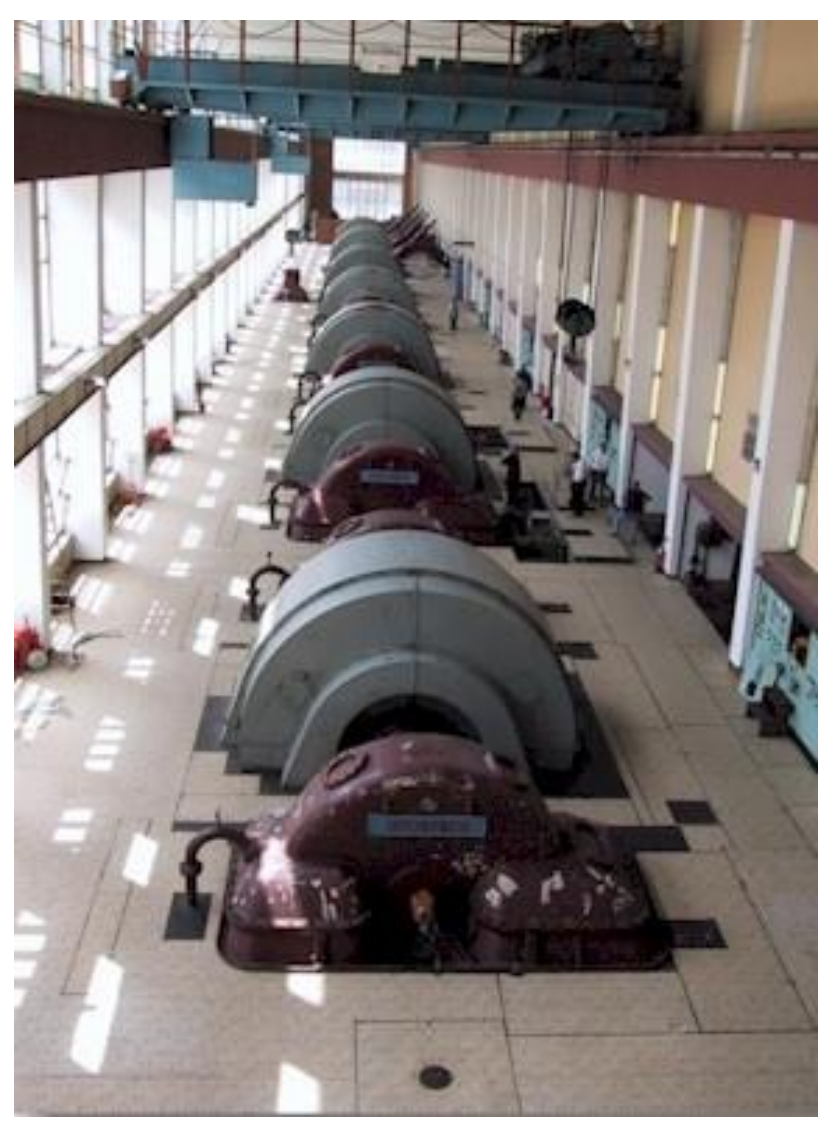

Fig.7. Perućica HPP powerhouse with seven Pelton turbine units

Numerical and measured heads at the turbine inlet $(H)$ for emergency shutdown of the unit $\mathrm{A} 1$ are compared in Fig.8b. The computed and the measured total needle closure times are the same (55.3 s - see Fig.8a). Maximum measured head of $557.7 \mathrm{~m}$ occurs when the nozzle is fully closed. Head rise for this case is $24.5 \mathrm{~m}$. Maximum calculated head is $556.4 \mathrm{~m}$ (two-speed closure; the cushioning stroke is $2.5 \%$ ). The maximum calculated head matches the measured one. Calculated and measured heads are much lower than the maximum permissible head of $602 \mathrm{~m}$. Fig.8c shows comparison between computed and measured rotational speed. The maximum measured turbine rotational speed rise of $8.1 \%$ occurs at time of full deflection of the jet (at $1.6 \mathrm{~s}$ ). The maximum computed turbine speed rise of $8.0 \%$ agrees well with the measured one. After jet deflector deflects all the water into the tailrace, the computed turbine speed decrease reasonably agrees with measured one. The maximum turbine inlet pressure head and the maximum speed rise are within the guaranteed limits.
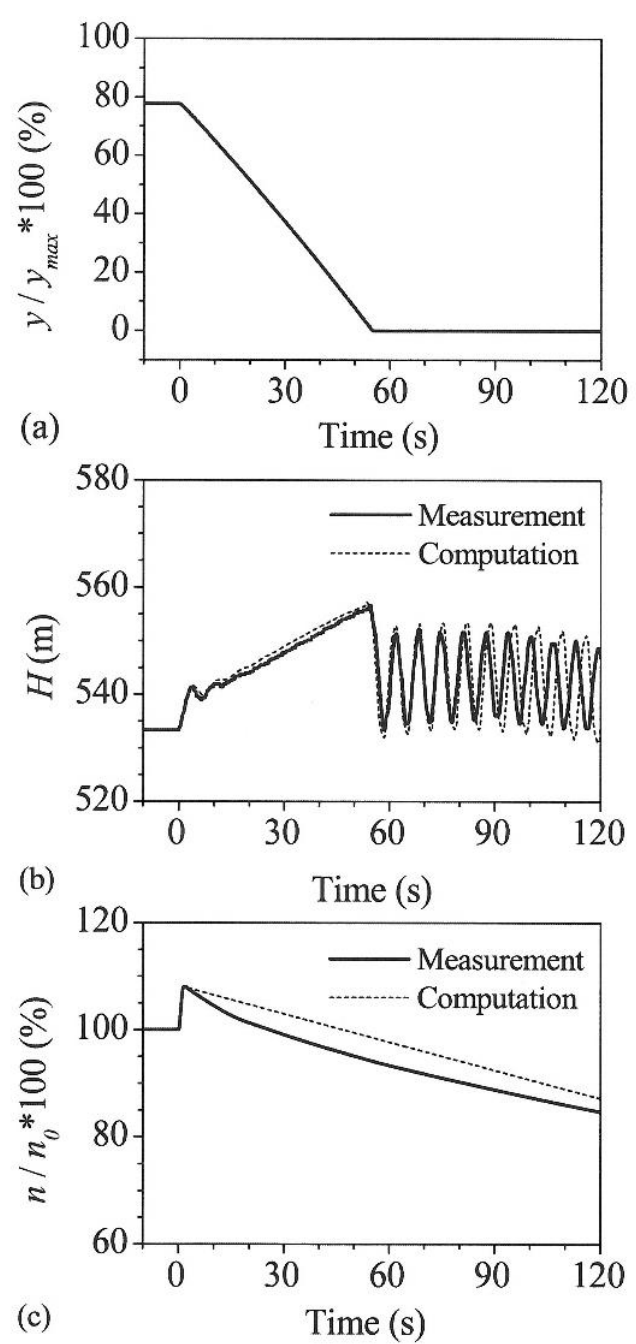

Fig.8. Emergency shutdown of one Pelton turbine in Perućica HPP $(P=39.5 \mathrm{MW})$ : Needle valve servomotor stroke $y(a)$, turbine inlet head $H(b)$ and unit rotational speed $n$ (c) [7]

\section{CONCLUSIONS}

Water hammer in hydropower plants is caused by turbine load acceptance and reduction, load rejection under governor control, emergency shutdown and unwanted runaway, and closure and opening of the safety shutoff valve. It induces pressure rise or drop in hydraulic systems, rotational speed variation in hydraulic turbomachinery (pumps and water turbines) and level fluctuation in surge tanks and air chambers.

The paper presents design principles of water hammer control strategies (mitigation of excessive loads) including operational scenarios (closing and opening laws), surge control devices (flywheel, surge tank, regulating valve, air valve, etc.) and redesign of the pipeline components. Classical theoretical water hammer models and solutions are briefly discussed in the light of their capability and availability. 
Case studies include hydropower plants with long fluid conveying systems (open channels, headrace and tailrace tunnels) and water hammer control devices (surge tank, regulating valve). Due to very long inflow and outflow open channels in Zlatoličje HPP a special vaned pressure regulating device attenuates extreme pressures in Kaplan turbine flow-passage system and controls unsteady flow in both open channels. Water hammer in inlet and outlet short conduits is controlled by appropriate adjustment of the wicket gates and runner blades closing/opening laws. Transients in long tunnel of Perućica HPP are controlled by cylindrical type surge tank with an expansion and overflow. Water hammer in the three penstocks that feed seven Pelton turbines is controlled by appropriate adjustment of the distributor needle valve closing/opening maneuvers. The agreement between computed and measured results for emergency shutdown cases in both hydropower plants is reasonable. Most important, water hammer control means keeping transient pressure head and turbine rotational speed rise within the prescribed limits.

\section{REFERENCES}

[1] P. Dörfler, M. Sick, Coutu, Flow-induced pulsation and vibration in hydroelectric machinery: engineer's guidebook for planning, design and troubleshooting. Springer Science \& Business Media, 2012.

https://doi.org/10.1007/978-1-4471-4252-2
[2] M.H. Chaudhry, Applied Hydraulic Transients. Springer, New York, NY, 2014.

[3] E.B. Wylie, V.L. Streeter, L. Suo, Fluid transients in systems. Englewood Cliffs, Vol.1, NJ: Prentice Hall, 1993.

[4] A. Zobeiri, C. Nicolet, E. Vuandes. Risk analysis of the transient phenomena in a hydropower plant installation. Hydro 2011, Prague, 2011.

[5] A. Anderson, A. Bergant, "Issues in 'benchmarking' fluid transients software models". In Proc. 10th International conference on pressure surges: surge analysis - system design, simulation, monitoring and control, BHR Group, Edinburgh, UK, 2008, pp.519-537.

[6] A. Bergant, B. Gregorc, J. Gale, Numerical and in-situ investigations of water hammer effects in Drava river Kaplan turbine hydropower plants, In IOP Conference Series: Earth and Environmental Science, IOP Publishing, Vol.15, No.5, p.052001, 2012.

[7] U. Karadžić, A. Bergant, P. Vukoslavčević, A novel pelton turbine model for water hammer analysis. Strojniški vestnik - Journal of Mechanical Engineering, 55 2009: 369-380

The shorter version of this research was presented at the "8nd International Scientific Conference IRMES 2017", 7 - 9 September 2017, Trebinje, Bosnia and Hercegovina. 